\title{
"The Effectiveness and Efficiency of the Various Graduate Recruitment Methods"
}

\author{
Abhishek Venkteshwar ${ }^{1},{\text { Nishesh } \text { Agarwal }^{2} \text { and Nilesh Singhvee }}^{3}$ \\ ${ }^{1}$ Assistant Professor-Centre for management Studies, Jain University, Bangalore \\ ${ }^{2}$ Student-Centre for management Studies, Jain University, Bangalore \\ ${ }^{3}$ Student-Centre for management Studies, Jain University, Bangalore
}

\begin{abstract}
:
Purpose: Research in the field of Recruitment and Selection have become a dynamic study area over the past few decades and is likely to become even more so as the importance of human resource management is rapidly gaining momentum. Therefore understanding the various recruitment methods will be viewed as increasingly important. The global-economy has undergone a drastic change over the last few years. Globalization, privatization, liberalization all contribute to this change. The global-economy has scaled great heights, but in the recent-past recession has been a major road block. There are several consequences to recession, but the major one has been job-cuts. Securing a job today is a challenging and complicated task and to add to the complexity, the recruitment procedure has changed completely over the years. This article aims at examining the effectiveness and efficiency of graduate-recruitment methods in today's world by using extensive literature review and secondary research.
\end{abstract}

Keywords: Graduate Recruitment, Recruitment Methods, Effectiveness, Efficiency and Recruitment Procedures.

\section{Introduction}

"Recruitment is the process of generating a pool of capable people to apply for employment to an organization."'(Gold 2007). It's impossible to develop every source of workforce to the fullest. Therefore for the purpose of achieving optimum success in obtaining competent workforce, organisations tend to evaluate, judge and utilize sources based on possible(perceived) degree of success. If organizations (recruiters) can establish a co-relation between successful workforce and the source of supply, then recruiters can focus on these sources and develop them with money and efforts. A continuing study by the Division of Research, Harvard Business School, suggests that a firm's image or style has something to do with the type of student talent it can attract. Firms are characterized by variables, such as: size, discouragement of risk taking, stability, emphasis upon profits, and well structured chain of command. So firms who want to attract graduates to work for them need to focus on these factors. According to Bach(2005)reliability is an important criteria to measure the effectiveness of the recruitment-procedure. "Reliability essentially refers to the consistency of a method used to select individuals."(Bach 2005) .Towards achieving a reliable method of recruitment, recruiters continue to develop different methods, which many institutions try to adopt as curriculum in their syllabus and encourage their students to participate in it. For example, some universities work with recruiters from various organizations and make their graduate-students aware of the job-specifications and the related competencies, use their faculty and external consultants to develop their students to meet the selection criteria, while they are pursuing their main discipline. This article will also examine and attempt to arrive at some conclusions on actions by recruiters that could bring a better probability of success in graduate recruitment process.

\section{"What is the city but the people? "-William-Shakespeare}

\section{Literature Review}

In this article the word city will be replaced by organisation and add beside people in parenthesis-jobs and performers. Firms set organization-goals. They design organization-structures, deploy-resources and manage-interfaces. But that is not enough; the firm has to then construct a building on this foundation based on performance of employees. When it comes to performance, selection is a key-aspect. "Selection involves the identification of the most suitable person from a pool of applicants."(Sparrow and Hiltrop,1994 cited in Brewester,SparrowandVernon,2007).

Graduate-recruitment is a part of the process of addressing current and future performancerequirements of organizations. We are using the nomenclature Job and Performer instead of people in context of recruitment because people are hired as resources for various positions to serve certain jobs in diverse situations in a Human-Performance system. In order to mobilize performers to address various jobs in organisations, recruiters tend to take these steps in graduate recruitment: public-relations, faculty-involvement, 
student-involvement, pre-placement-presentations, job-fairs, conduct selection-processand feedbackmechanism.

Harris(1997) has suggested certain steps for campus-recruitment and i.e. prescreening-applicants, variety of means for attracting-applicants, effective use of recruitment-materials and evaluating the cost-benefits of recruitment-program. The success of the recruitment can be judged by utilizing number of criteria, such as number of factors like applicants, offers made, hiring andsuccessful placements, therefore following factors play important role creating the expectations among the candidates a)attractiveness which includes reputation of the organisation, job and level, compensation, future value (in terms of the job, industry and organisation association), growth opportunity (both within and outside the organisation), job posting and social standing, b)performance(what needs to be achieved)consists of eligibility conditions(grade, discipline, etcetera), perceived standards of assessment process, the assessment process, etc, c)efforts(performance related activity)includes ability, willingness, preparedness and prioritization and d)consequences consists of post placement continuity (within first 12 to 36 months).

Though recruiters apply various approaches (depending on their means and resource capability), but the true test of a recruitment programme is possible if there is data and research to provide answers to the following questions:

- Was the placement successful?

- Did the employee quit because of misunderstanding the nature of job

- Is the person a good employee in terms of productivity and attitude?

Admittedly, such an evaluation will include an appraisal of the selection procedure, and believe that one can properly evaluate the recruitment if only there is information available to establish relationship among some of the above factors with regards to achieving the end result, 'successful-placement'. CIPD 2010(2009) lists some methods used to select applicants.

\begin{tabular}{|l|c|}
\hline METHOD used to select applicants & \% use (N = 473 (754)) \\
\hline Competency-based interview & $78(69)$ \\
\hline Interview following CV / application form & $64(68)$ \\
\hline Structured interview (panel) & $61(59)$ \\
\hline Tests for specific skills & $48(50)$ \\
\hline Telephone interviews & $47(38)$ \\
\hline Personality/aptitude/psychometric questionnaires & $44(35)$ \\
\hline Literacy/numeracy tests & $43(39)$ \\
\hline Assessment centres & $42(35)$ \\
\hline Group exercises & $30(26)$ \\
\hline General ability tests & $27(44)$ \\
\hline Pre-interview references & $16(19)$ \\
\hline
\end{tabular}

(CIPD 2010, (2009))

The effectiveness and efficiency of the recruitment process will depend on perception of performance (of the selection process) in terms of the standard and quality of the process and efforts required to address the required performance both by the recruiter and candidate. Hence the various approaches of setting performancestandards need to be evaluated by examining the following graduate-recruitment processes

- Standalone-processes: basic graduate selection processes and competency based assessment-centers

- Collaborative-learning-focused-process: systemic process(integrated) having collaborative-approach.

\section{Standalone-processes:}

In Standalone-processes, the Basic Graduate selection process(mass-recruitment) will be discussed in detail .It is a template process, used regularly and repeatedly, hence generally applied in mass-recruitment. Being templated and repetitive process, it can be outsourced to outside agencies. The objective is to evaluate job fitment in terms of basic qualification, technical capabilities, general awareness, team work and attitude. The procedure includes a written test:[technical and aptitude], behavioral: [psychometric tests,-“"from a psychometric perspective ,selection and assessment are concerned with finding methods to measure the individual differences more accurately so that individual and jobs can be appropriately-matched."(Redman and Wilkinson 2006) and psychological-assessment ,team-work:[group-discussion],interview: [technical and human-resources] and demonstration[practical-experience, problem-solving or presentation].The advantages are that it's easy to apply, can be outsourced, is an efficient process, it's fairly successful in resource mobilization for technical jobs and the selection process is cost effective.

The disadvantages of this process is that its indifferent to people's needs and aspiration, post placement continuity is poor, quality is not consistent and overall cost is expensive. Most of the new companies follow this kind of recruitment. 
The second method is the Competency based assessment centers (leadership development), which is a systematic process of developing assessment-procedures based on identified characteristics which produce successful performance(competencies) for the position with regards to the organization and its situations. "Competency is used to describe all the personal attributes, knowledge, skills and values that a person draws on to perform their work well."(Roberts 2005). The process focuses on discovering in candidates set of behaviours that the organisation finds necessary for performance in the job.It is a customized process applied by trained-administrators, assessor's and raters who use various techniques and tolls to discover these competencies among candidates.

\begin{tabular}{|l|}
\hline Generic Graduate Employability Competencies \\
\hline Communication skills \\
\hline Teamwork and relationship building abilities \\
\hline Time and management skills \\
\hline The ability to see the bigger picture \\
\hline Influencing and persuading abilities \\
\hline Problem solving abilities \\
\hline Leadership abilities \\
\hline Presentation skills and abilities \\
\hline
\end{tabular}

Generic Graduate Employability Competencies (Higson and Andrews 2007)

Organizations applying this process believe that it can identify high quality performers on whom the company can invest for developing future-leaders. The objective is to evaluate overall fitment of the candidate based on basic eligibility-criteria andset of identified competencies for the job. In this process ,evaluation of candidate can involve varieties of methods like behavioral Event Interviews( coded as per competencies),Tests( to measure one or more competencies),Assessment center(simulation exercises requiring the test taker to generate behavior, usually in situation with other people, coded for one or more competencies) and Bio-data.The advantages are that is very systematic method, highly effective as various correlations are established for accurate rating, focused on recruiting candidate for both present future contributions, uses trained facilitators and consultants and with time neutralizes the high initial cost.

The disadvantages are that it requires extensive planning and preparation, difficult for organizations to apply in case they haven't already identified competencies for the job, requires thorough understanding of process to apply, hence cannot be just outsourced to anyone and initial cost of selection is high. In 1990,a popular software MNC had started its branch in Mumbai,India,The organization could only import some of its employees from its home country, it needed to recruit the locals and that is when it designed the competency based approach ,that approach was relatively a new approach in India. The organization made their candidates go through this procedure and selected only the most competent candidate. This started a trend and there on many MNC's started following this procedure. Most of the candidates today have to go through this procedure to secure a job in a MNC. This method is universally followed and is considered a prominent way to select its prospective employees.

\section{Collaborative-learning-focused-process:}

Collaborative and learning focused selection process (organisation development) is a systematic and integrated process between institutions and recruiting organizations, planned and developed in a collaborative way between these two parties as a part of organisation development initiative to address both short and long term strategic goals of the firms. The process includes a series of planned initiatives between specialized faculties, graduate students of the institution and key members of the recruiting organization, to identify performance needs across performance levels. Then, identifying competencies and eligible candidates, selection process, people development and placement processes. The whole process is integrated in a way that each entity supports the other to produce some result, actively creating awareness and familiarizing with each other's processes, culture and challenges. The objective of this procedure is to evaluate candidates from a group who are aware of the job and familiar with the organization's situations and have experience to perform successfully when placed. The procedure includes pre-selection (placement) integration and selection. In pre-selection integration, the recruitment organization should identify key areas of organization development, Identify institutions and Select leaders and teams and then the institution should establish links with organizations and participate in request for proposals (RFP). 


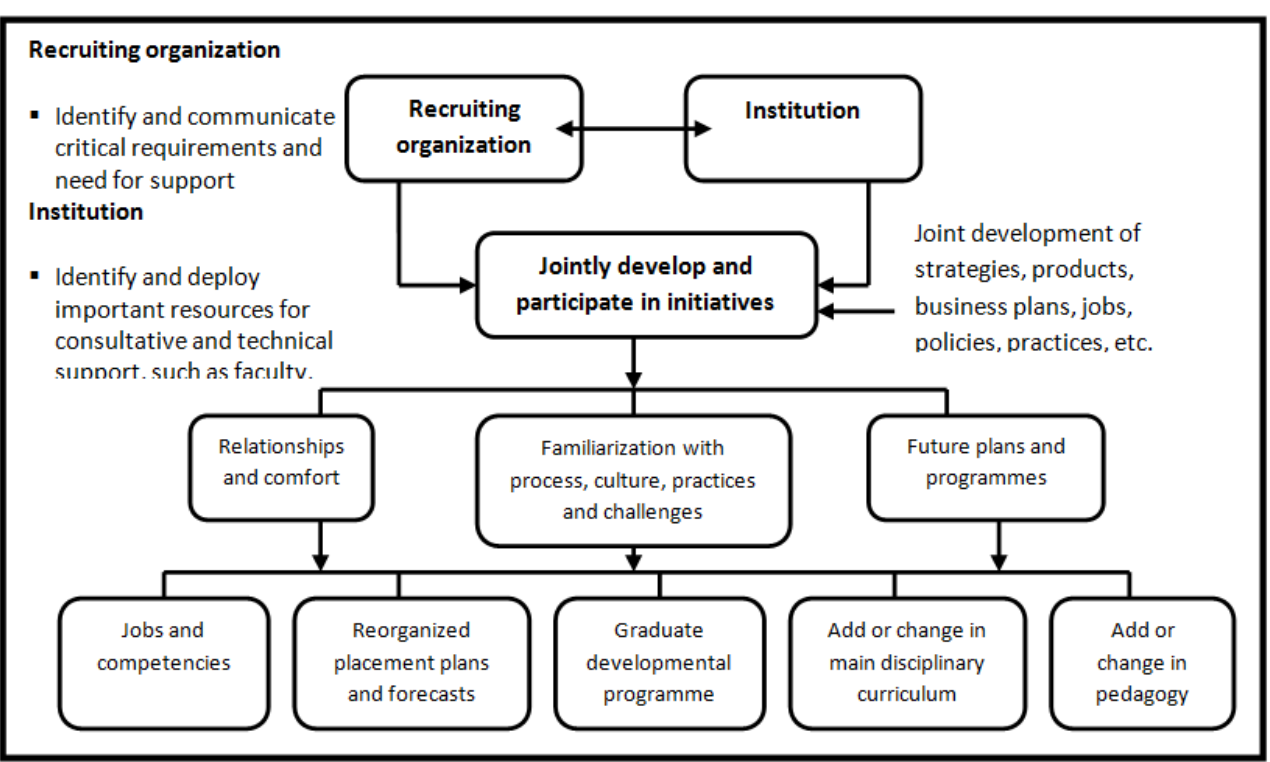

Figure 1: the figure depicts scope of collaboration to create predictable opportunities of placing graduate students successfully by an integrated and systematic process.

Then jointly they have to do the team formation, project evaluation and record performance of key graduate-student resources. In selection, the institute has to identify jobs and competencies in collaboration with the organization recruiters, identify key jobs for graduate students, their job descriptions and competencies, then develop candidates based on the competencies and prepare them. The recruitment organization has to invite applications, conduct selection-process, bio-data, competency based assessment center, stake holder rating(by referring to the records of performance) then finally review and rating(Ranked order correlations) .The advantages are that it is an extremely effective and successful process, predictable and deterministic process, improves reputation and value of the institution, relationship with the organization and improvement in the method of teaching .The disadvantages are that it can hurt the institution's reputation if lacking in distinction and discipline, requires high efforts and involvement of both organizations and it is a cost effective process for specialized functions.

Recent studies list the following assessment methods in descending order of criterion validity correlations with job-performance:

\begin{tabular}{|l|l|}
\hline Assessment Method & $\boldsymbol{r}$ \\
\hline Assessment centers & $\mathbf{0 . 6 5}$ \\
\hline Interviews (behavioral) & $\mathbf{0 . 4 8}-\mathbf{0 . 6 1}$ \\
\hline Work sample tests & $\mathbf{0 . 5 4}$ \\
\hline Ability tests & $\mathbf{0 . 5 3}$ \\
\hline "Modern" personality tests & $\mathbf{0 . 3 9}$ \\
\hline Bio-data & $\mathbf{0 . 3 8}$ \\
\hline References & $\mathbf{0 . 2 3}$ \\
\hline Interviews (non-behavioral) & $\mathbf{0 . 0 5}-\mathbf{0 . 1 9}$ \\
\hline
\end{tabular}

During the year 1997, a well-established bank in Bangalore faced a huge crisis; there was a huge demand but shortage of employees. The bank had lost their employees because of their company-policies. The bank was in a very bad state and it needed to recruit employees immediately, so it collaborated with a leading institution in the country and got academicians and existing employees to train the students and followed the collaborative recruitment method i.e., it used the above steps to recruit its employees from the institution and managed to come out of the crisis in a short period. This set a trend and thereafter many organizations tied up with institutions and followed the collaborative approach to recruit its employees. Infact many banks, financialinstitutions have started using this approach. Today most of the established universities in the world are tied up with one or the other recruitment-organizations.

\section{Observation}

On completing an extensive secondary research and literature review, the following conclusions can be made.

1. There is no structured manual which clearly indicates the kind of recruitment procedure to be used for graduate recruitment.

2. There are no clear comparisons between the various methods of recruitment and selection in graduate recruitment. 
This clearly indicates that there is a need to develop a conceptual model that clearly differentiates between the different processes. This has been illustrated. In the conceptual model

\section{Research Gap}

Research has been conducted extensively on the various recruitment procedures. However, little research has been conducted on the comparison between these procedures This research aims at filling this gap by understanding how differenent each procedure is from the other .

\section{Conceptual Model}

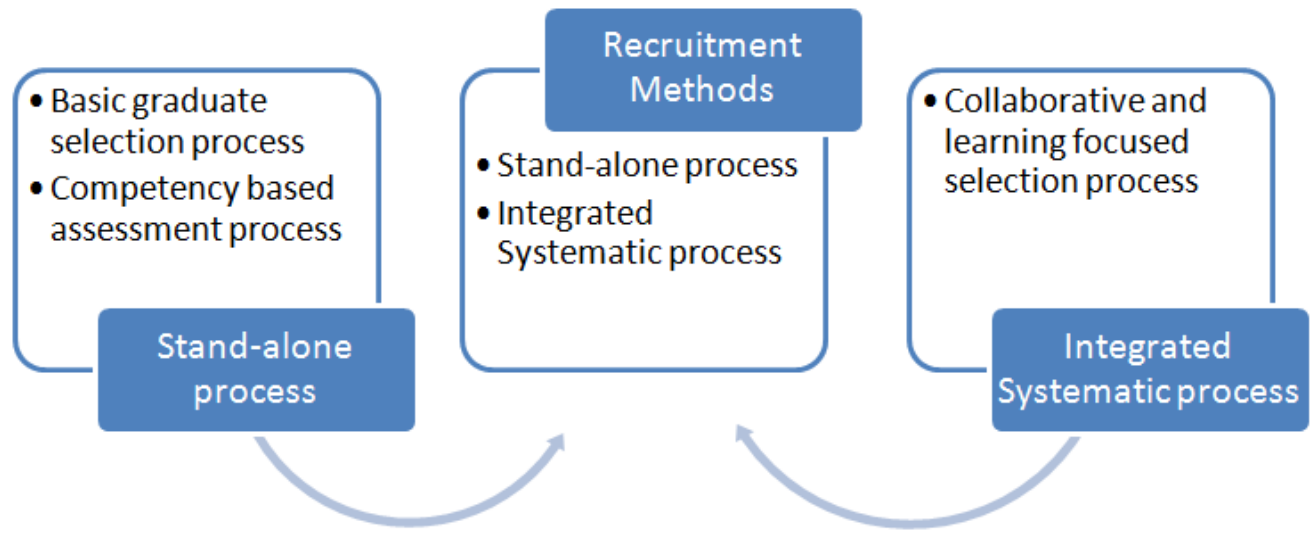

\begin{tabular}{|c|c|c|c|}
\hline & \multicolumn{2}{|c|}{\begin{tabular}{|l} 
Stand alone processes \\
\end{tabular}} & \multirow{2}{*}{$\begin{array}{l}\text { Integrated systematic process } \\
\text { Collaborative and learning focused } \\
\text { selection process }\end{array}$} \\
\hline Aspects & $\begin{array}{l}\text { Basic graduate selection } \\
\text { process }\end{array}$ & $\begin{array}{l}\text { Competency based assessment } \\
\text { process }\end{array}$ & \\
\hline 1. Description & $\begin{array}{l}\text { Templated } \\
\text { Can be used repeatedly } \\
\text { Can be replicated by an } \\
\text { outsourced agency }\end{array}$ & $\begin{array}{l}\text { Highly systematic evaluation } \\
\text { process involves developing } \\
\text { customized assessment centers and } \\
\text { behavioral interviews coded by } \\
\text { identified competencies of the job }\end{array}$ & $\begin{array}{l}\text { Systematic and integrated process } \\
\text { involving collaboration between the } \\
\text { recruiting organisation and the } \\
\text { institutions for a period of time. }\end{array}$ \\
\hline 3. Process & 5 main steps and 7 activities & $\begin{array}{l}4 \text { main steps and } 7-10 \\
\text { customized activities }\end{array}$ & $\begin{array}{l}16 \text { integrated steps with many } \\
\text { activities }\end{array}$ \\
\hline 4. Ease of use & Can be easily replicated & $\begin{array}{l}\text { Requires trained administrators, } \\
\text { assessors and raters. }\end{array}$ & $\begin{array}{l}\text { Requires collaboration and } \\
\text { commitment of key people and } \\
\text { resources. }\end{array}$ \\
\hline 6. Disadvantage & $\begin{array}{l}\text { Indifferent to people, } \\
\text { inconsistent quality, post } \\
\text { placement continuity is poor } \\
\text { and overall high cost of } \\
\text { quality }\end{array}$ & $\begin{array}{l}\text { Requires extensive planning and } \\
\text { preparation } \\
\text { Can't apply unless have already } \\
\text { identified competencies } \\
\text { Initial cost is high }\end{array}$ & $\begin{array}{l}\text { Can hurt the institution's reputation } \\
\text { if lacking in distinction and discipline } \\
\text { Requires high efforts and } \\
\text { involvement of both organisations }\end{array}$ \\
\hline $\begin{array}{l}\text { 7. Best applied } \\
\text { at }\end{array}$ & $\begin{array}{l}\text { Mass recruitment in } \\
\text { technical sections }\end{array}$ & $\begin{array}{l}\text { Recruitment of management } \\
\text { trainees }\end{array}$ & $\begin{array}{l}\text { Recruitment of high potential } \\
\text { candidates and specialized talents }\end{array}$ \\
\hline
\end{tabular}

The Conceptual Model explains the effectiveness and efficiency of the graduate-recruitment by in-depth analysis of the different approaches of graduate-recruitment processes.

\section{Conclusion}

In this article the different approaches of graduate-recruitment processes have been examined to provide an opportunity to the reader to judge the effectiveness and efficiency of these processes. It can be concluded by reinforcing the fact that each process has its own merit and demerit and can be judiciously applied based on specific needs.. Even though various procedures are applied, none of them can accurately measure the potential of the candidate and wrong judgments are consistently being made in organizations. Who is to blamethe organization, the candidates or the system itself??? 
Nobody has an answer to this, the day this question gets an answer; an universal recruitment procedure can be derived. This research will be taken forward by conducting a primary research on 25 different MNC's about their recruitment procedures to try and find the answer to the question.

\section{Reference}

[1]. Chris Brewster, Paul Sparrow and Guy Vernon (2007). International Human Resource Management. 2nd edition. London: Chartered Institute of Personnel and Development

[2]. CIPD (2009) Recruitment, retention and turnover, Annual Survey Report, London, CIPD.

[3]. CIPD (2010) Resourcing and Talent Planning, Annual Survey Report, London, CIPD.

[4]. Edwin B Flippo (1984) Personnel Management. (which was previously printed under the title: Principles of Personnel Management). Sixth Edition .McGraw-Hill international editions

[5]. Gareth Roberts (2005). Recruitment and selection. 2nd edition. London: Chartered Institute of Personnel and Development.

[6]. Garry A Rummler and Alan P Brache(1995), Improving Performance, How to manage the White space on the organisation chart, Second Edition (revised and updated) ed.Jossey - Bass Publsihers, San Francisco.

[7]. Goleman, D. (2008). What makes a leader : Harvard Business Review.

[8]. Greenberg Jerald and Baron Robert A (2008). Behavior in Organizations. Ninth. ed. New Jersey: Pearson Education, Inc.

[9]. Hijazi, Syed Tahir and Naqvi, S.M.M. Raza. (January 2006). 'Factors Affecting Students' Performance: A Case of Private Colleges'. Bangladesh e-Journal of Sociology: Volume 3, Number 1.

[10]. Higson, H. and Andrews, J. (2007) Education, Employment and Graduate Employability: Project Manual. Aston Centre for Research into Higher Education, Learning and Management, Aston University.

[11]. Higson, H. and Andrews, J. (2007) Education, Employment and Graduate Employability: Project Manual. Aston Centre for Research into Higher Education, Learning and Management, Aston University.

[12]. John Bratton and Jeff Gold (2007). Human Resource Management Theory and Practice. 4th edition. New York: Palgrave Macmillan.

[13]. Lyle L Spencer Jr, Phd and Signe M Spencer( 2010) Competency at work, models for superior performance .reprint edition.Wiley India Pvt. Limited.

[14]. Michael Harris (1997). Human Resource Management : A Practical Approach. First. ed. Florida: Harcourt Brace and Company

[15]. Stephen Bach (edited). (2005). Managing Human Resources : Personnel Management in Transition ,4th edition .Oxford Blackwell Publishing Ltd.

[16]. Stephen P Robbins (2001) Organization Behavior, 9th edition, Pearson Education Asia

[17]. Shipley, L, Jackson, M and Segrest, S. (2010). The effects of emotional intelligence, age, work experience and academic performance. Research in Higher Education Journal

[18]. Weinberger, L.(2002).Emotional Intelligence: Its connection to HRD theory andpractice.HumanResourceDevelopment Review,1(2)

[19]. Stephen P Robbins (2001) Organization Behavior, $9^{\text {th }}$ edition, Pearson Education Asia

[20]. Tom Redman and Adrian Wilkinson (2006). Contemporary Human Resource Management : Text and Cases. Second edition. Essex: Pearson Education Limited 